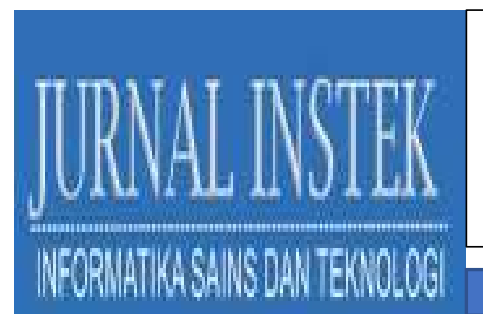

Volume 6 Nomor. 1, April 2021

P-ISSN : 2541-1179, E-ISSN : 2581-1711

Ojs :http://journal.uin-alauddin.ac.id/index.php/instek/index

Email : instek@uin-alauddin.ac.id

\title{
DESAIN 3D KEMASAN MINYAK WANGI APLIKASI CAD (COMPUTERED AIDED DESIGN) DENGAN METODE API (ANALYSIS PRODUCT INSPECTION)
}

\author{
MOCHAMMAD MUCHID \\ Fakultas Teknik Universitas Wijaya Putra \\ Email : muchid@uwp.ac.id
}

\begin{abstract}
ABSTRAK
Pembuatan produk yang sempurna tidak terlepas dari proses design yaitu 3D modeling \& 2D Drawing. Penelitian ini bertujuan adalah membuat rancangan model 3D pada produk kemasan minyak wangi dengan aplikasi CAD, Menghitung hasil pengukuran tutup kemasan minyak wangi secara CPK (Penyimpangan) dan secara Average (rata-rata). Metode yang digunakan pada penelitian ini adalah pengambilan data keputusan menggunakan api (analysis product inspection). Hasil penelitian yang diperoleh adalah hasil pengukuran tutup kemasan minyak wangi secara CPK (penyimpangan) mendapatkan hasil $0.89,0.08,-0.41$ dan 0.40 diantara nol dan satu menandakan rata-rata proses terletak dalam batas spesifikasi tetapi bagian variasi terletak diluar spesifikasi. Hasil Pengukuran tutup kemasan minyak wangi Secara average, terdapat angka yang berwarna merah yang menandakan dimensi inspection keluar dari basic dimensions khususnya pada point nomer 3 sample 1 sampai 5 semuanya keluar dari batas toleransi .
\end{abstract}

Kata Kunci : Model 3D, Aplikasi CAD, API

\section{I.PENDAHULUAN}

Dunia injection plastic pada Era New Normal saat ini sangat meningkat tajam, dikarenakan banyak permintaan pasar membuat packaging (botol handsanitazer, air mineral dalam kemasan, dan tepak makan) dimasa Covid 19 ini pemerintah menganjurkan pembatasan sosial dengan anjuran pembelian makanan harus dibawa pulang, semakin meningkatnya product plastic maka tumbulah peluang usaha satu dan lainnya yang menciptakan pengusaha baru, selain itu juga berkesinambungan dengan proses manufacture yang ada saat ini guna pengadaan peralatan atau permesinan yang memadai.Tekik industri tentunya sudah tidak asing lagi didalam penggunaan aplikasi CAD (Computered Aided Design), untuk menciptakan produk yang berkualitas tinggi dengan sedikit pengeluaran dengan adanya prototype (tiruan produk) hampir 80,000 perusahaan didunia saat ini menggunakan SolidWork, 


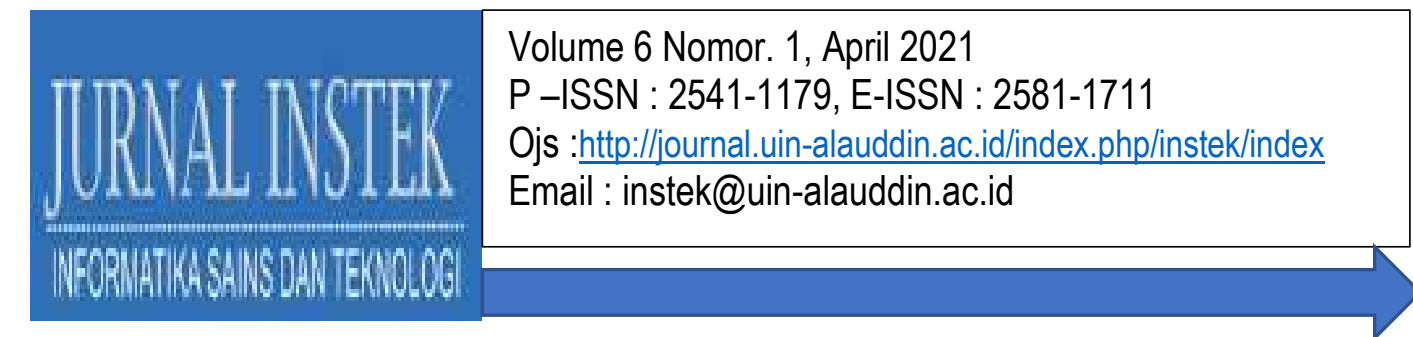

SolidWork adalah salah satu CAD software yang dibuat oleh DASSAULT SYSTEMES digunakan untuk merancang part permesinan atau susunan part permesinan yang berupa assembly dengan tampilan 3D untuk merepresentasikan part sebelum real part nya dibuat atau tampilan 2D (drawing ) untuk gambar proses permesinan, SolidWork juga dilengkapi dengan analisa atau prediksi mekanika kekuatan material (fatique, frequency, buckling, thermal, drop test, computetred fluid dynamic, plastic, computered aided manufacture dan lain sebagainnya).

Pembuatan produk yang sempurna tidak terlepas dari proses design yaitu 3D modeling \& 2D Drawing, permesinan yaitu pembuatan cetakan menggunakan CNC 5 axis, proses cetak yaitu proses masal pembuatan produk menggunakan mesin injection dan inspection yaitu proses melakukan pengukuran produk sebelum diproduksi masal (jumlah banyak) dari ketiga usur itulah kalau terpenuhi maka menghasilkan produk yang berkualitas.

Computer Aided Design adalah suatu program komputer untuk menggambar suatu produk atau bagian dari suatu produk. Produk yang ingin digambarkan bisa diwakili oleh garis-garis maupun simbol-simbol yang memiliki makna tertentu. CAD (Computered Aided Design) bisa berupa gambar 2 dimensi dan gambar 3 dimensi.Berawal dari menggantikan fungsi meja gambar kini perangkat lunak CAD telah berevolusi dan terintegrasi dengan perangkat lunakCAE (Computer Aided Engineering) dan CAM (Computer Aided Manufacturing). Integrasi itu dimungkinkan karena perangkat lunak CAD saat ini kebanyakan merupakan aplikasi gambar 3 dimensiatau biasa disebut solid modelling.

Didalam penelitian ini yang menjadi permasalahan yang pertama adalah adanya pengambilan keputusan status produk yang dilakukan departemen quality control dalam penyajian dan pengolahan data masih menggunakan manual tidak automasi sehinga memungkinkan pengolahan data (penjumlahan dan pembagian) sering salah, dan menyebabkan pengukuran kembali, serta tidak adanya nomer registrasi inventaris dan kalibrasi sehinga penggunaan alat ukur diperlakukan sama, seharusnya alat ukur mempunyai penyimpangan sendiri-sendiri hal inilah yang 
berpotensi gagal, yang akan berdampak pada moulding injection diatas mesin tetapi tidak beroperasi yang mengakibatkan proses produksi tertunda dan mengakibatkan kerugian pada perusahaan.

\section{II.METODE PENELITIAN}

Metode didalam pengambilan data keputusan menggunakan API (analysis product inspection) adalah suatu template dengan format ms excel yang didalamnya terdapat perumusan atau formula yang telah dibuat sehingga dapat memberikan informasi langsung, apabila dimensi produk ditulis dengan dengan data sebenarnya dengan kondisi melebihi dari toleransi yang di standarkan atau kurang maka gradiasi warna dapat berubah menjadi merah, serta memberikan info penyimpangan yang terjadi dalam inspection produk, serta dapat memberikan info hasil rata-rata pengukuran produk dengan automasi, apabila hasil salah maka dapat secara automasi menjawab nilai average dan gradiasi merah dan mampu membuat hasil keputusan benar dan salah secara automasi.

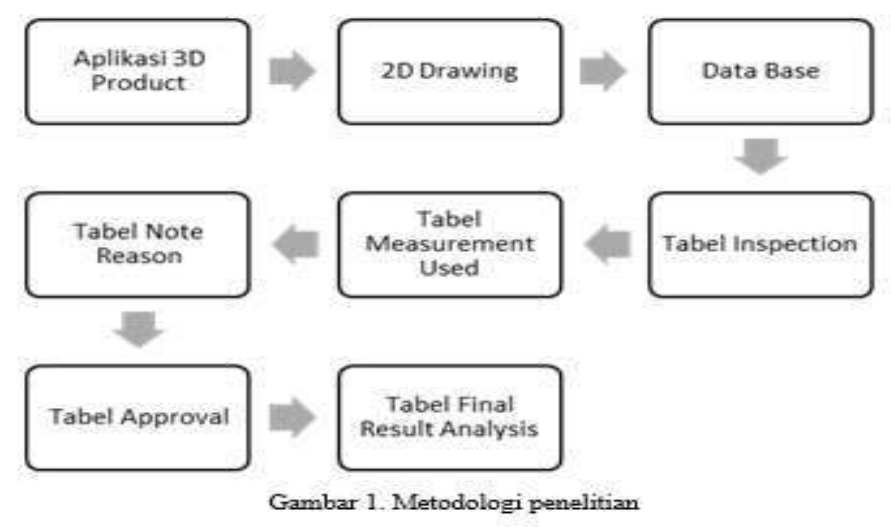

Dari gambar 1 metode pelaksanaan penelitian yang dilakukan adalah membuat perumusan template API (Analysis Product Inspection) dengan mengkonsepkan yaitu :

\section{- Date Base}

Suatu format susunan yang berisikan devision, Date Inspection, Drawing, Supplier dan Customer 


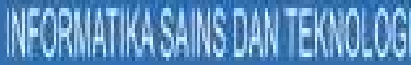

- Tabel Inspection

Suatu format berbentuk tabel yang didalamnya terdapat no, dimension tolerance, upper limit, lower limit, example 1-5 cpk, average, true and false, sudah diberikan formula

- Tabel Measurement Used

Suatu format berbentuk tabel yang didalamnya terdapat no, measurement, long \& hight, code inventaris and register calibration

- Tabel Note Reason

Suatu format berbentuk tabel yang didalamnya terdapat text this is API (Analysis Product Inspection)

- Tabel Approvel

Suatu format berbentuk tabel yang didalamnya terdapat nama dan tanda tangan dari supplier, quality control, riset \& devlopment and purchasing

- Tabel Final Result Analysis

Suatu format berbentuk tabel yang didalamnya terdapat instruksi Check list pass and reject

\section{III.Hasil dan Pembahasan}

\section{A. Hasil pembuatan Template API (Analysis Product Inspection)}

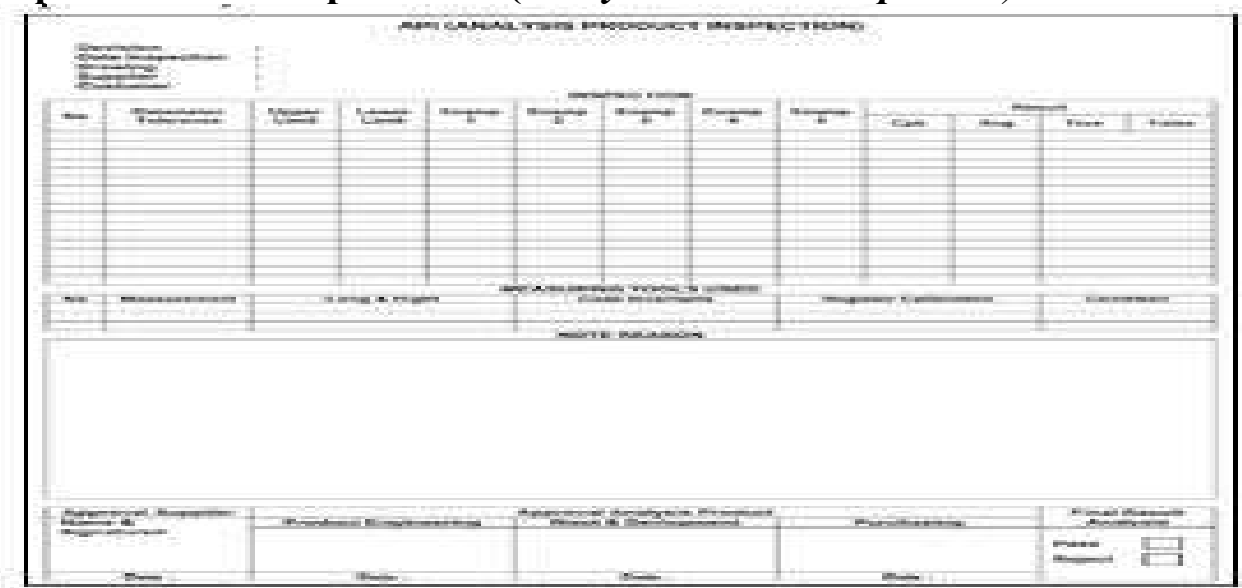

Gambar 2. Hasil pembuatan template API (Analysis Produk Inspection)

Hasil pembuatan template API (Analysis Product Inspection) ini dibuat dengan semudah mungkin penggunaannya sudah dilengkapi dengan formula APK, AVG dan Final Result serta file sudah dipastikan dikunci formulanya agar tidak berubah pada saat digunakan 


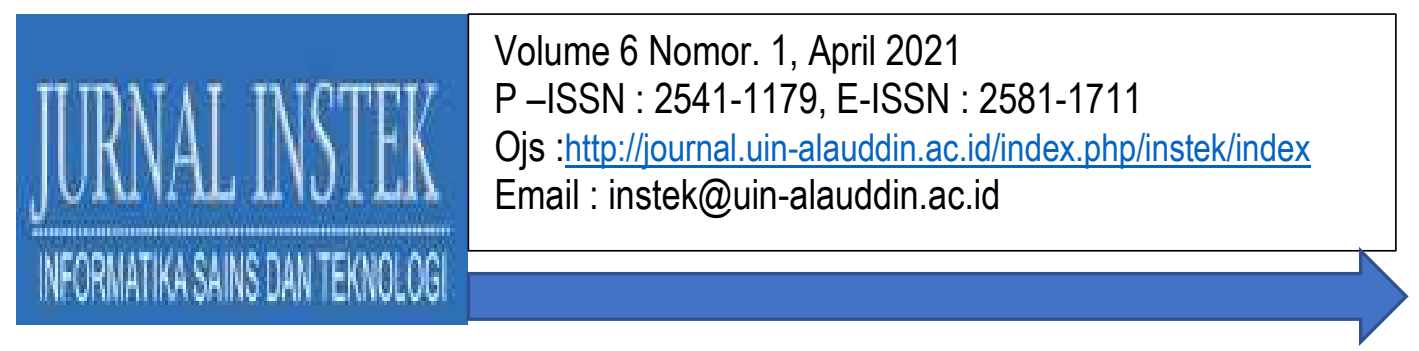

\section{B. Hasil 3D Modeling Product Kemasan Minyak Wangi}

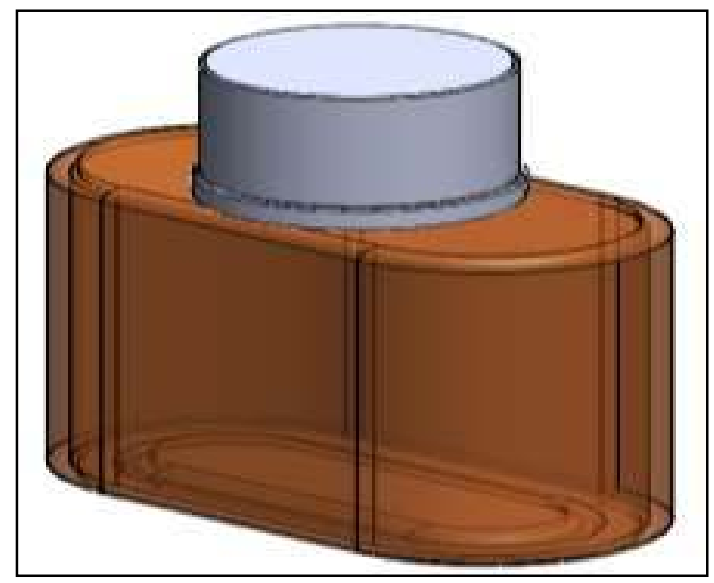

Gambar 3. Hasil 3d modeling produk kemasan minyak wangi

Pemodelan ini menggunakan Software SolidWork 2018 dengan mengambil contoh kemasan minyak wangi. Kemasan minyak wangi memiliki beberapa komponen yang mempunyai fungsi berkaitan dengan komponen yang lainnya, dan berikut dibawah ini gambar 2. Potongan kemasan minyak wangi. Pada gambar potongan dapat dilihat

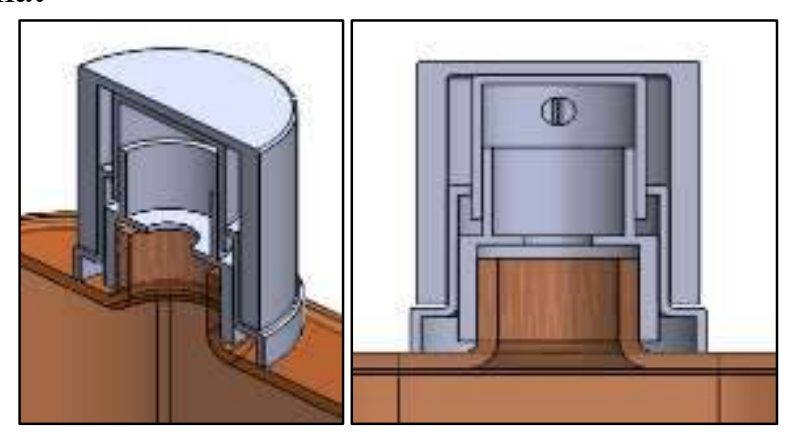

Gambar 4. Hasil 3D Modeling Section View

\section{Hasil Pengolahan Data}

Data inspection awalnya ditulis manual dikertas yang kosong, pengukuran tutup kemasan minyak wangi dilakukan menggunakan digimatic caliper $200 \mathrm{~mm}$ dan akan dilanjutkan dengan memindahkan data di API (Analysis Data Inspection).

- Hasil Pengisihan Data Inspection di API (Analysis Product Inspection) 


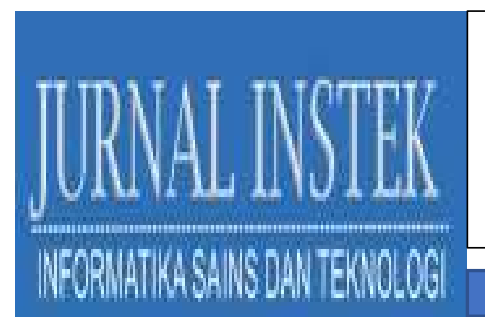

Volume 6 Nomor. 1, April 2021

P-ISSN : 2541-1179, E-ISSN : 2581-1711

Ojs :http://journal.uin-alauddin.ac.id/index.php/instek/index

Email : instek@uin-alauddin.ac.id

Tabe1 1. Inspection

\begin{tabular}{|c|c|c|c|c|c|}
\hline $\begin{array}{c}\text { Basic } \\
\text { Dimension }\end{array}$ & Ex-1 & Ex-2 & Ex-3 & Ex-4 & Ex-5 \\
\hline $\boldsymbol{\varnothing 2 1 . 0 \pm 0 . 2 0}$ & 21.10 & 21.20 & 21.20 & 21.10 & 21.20 \\
\hline $\boldsymbol{\varnothing 1 6 . 5 0}+0.00$ & 16.40 & 16.50 & 16.60 & 16.50 & 16.40 \\
\hline $\boldsymbol{\varnothing 2 1 . 6 5 _ { - 0 . 5 0 } ^ { + 0 . 3 0 }}$ & 21.0 & 21.0 & 21.0 & 21.0 & 21.20 \\
\hline $\boldsymbol{\varnothing 1 8 . 5 0 \pm 0 . 2 0}$ & 18.60 & 18.40 & 18.70 & 18.60 & 18.40 \\
\hline
\end{tabular}

Pada tabel 1 Menunjukkan hasil pengukuran tutup kemasan minyak wangi secara data pada point 2,3 dan 4 pada produk terdapat angka berwarna merah yaitu menunjukan pada bagian inspection tersebut keluar dari batas basic dimension.

- Hasil API (Analysis Product Inspection) Perpoint CPK

Hasil CPK terdapat rata-rata dari hasil inspection per point bervariasi ini tergantung dengan hasil pengukuran diawal yang bervarian

Tabe1. 2 Hasil pengukuran

tutup kemasan minyak wangi secara CPK

\begin{tabular}{|c|c|c|c|c|c|}
\hline $\begin{array}{c}\text { Basic } \\
\text { Dimension }\end{array}$ & $E x-1$ & Ex-2 & Ex-3 & $E x-4$ & Ex-5 \\
\hline $021.0 \pm 0.20$ & 21.10 & 21.20 & 21.20 & 21.10 & 21.20 \\
\hline$\varnothing 16.50_{-0.15}^{+0.00}$ & 16.40 & 16.50 & 16.60 & 16.50 & 16.40 \\
\hline $621.65_{-0.50}^{+0.30}$ & 21.0 & 21.0 & 21.0 & 21.0 & 21.20 \\
\hline $618.50 \pm 0.20$ & 18.60 & 18.40 & 18.70 & 18.60 & 18.40 \\
\hline $\begin{array}{c}\text { Basic } \\
\text { Dimension } \\
\end{array}$ & СРК & & & & \\
\hline 021.0 & 0.89 & & & & \\
\hline$\varnothing 16.50_{-0.15}^{+0.00}$ & 0.08 & & & & \\
\hline$\varnothing 21.65_{-0.50}^{+0.30}$ & -0.41 & & & & \\
\hline $018.50 \pm 0.20$ & 0.40 & & & & \\
\hline
\end{tabular}

Pada tabel 2 menunjukkan hasil pengukuran tutup kemasan minyak wangi secara CPK (Penyimpangan) pada point 1, 2, 3 dan 4 terdapat nilai yang berwarna merah yang menandakan terdapat penyimpangan setiap produknya. 
Volume 6 Nomor. 1, April 2021

P-ISSN : 2541-1179, E-ISSN : 2581-1711

Ojs :http://journal.uin-alauddin.ac.id/index.php/instek/index

Email : instek@uin-alauddin.ac.id

- Hasil API (Analysis Product Inspection) Perpoint AVG

Tabe1. 3. Hasil pengukuran

tutup kemasan minyak wangi secara average

\begin{tabular}{|c|c|c|c|c|c|}
\hline $\begin{array}{c}\text { Basic } \\
\text { Dimension }\end{array}$ & Ex-1 & Ex-2 & $E x-3$ & Ex-4 & Ex-5 \\
\hline $621.0 \pm 0.20$ & 21.10 & 21.20 & 21.20 & 21.10 & 21.20 \\
\hline$\varnothing 16.50_{-0.15}^{+0.00}$ & 16.40 & 16.50 & 16.60 & 16.50 & 16.40 \\
\hline$\varnothing 21.65_{-0.50}^{+0.30}$ & 21.0 & 21.0 & 21.0 & 21.0 & 21.20 \\
\hline$\varnothing 18.50 \pm 0.20$ & 18.60 & 18.40 & 18.70 & 18.60 & 18.40 \\
\hline $\begin{array}{c}\text { Basic } \\
\text { Dimension }\end{array}$ & AVG & & & & \\
\hline 021.0 & 21.120 & & & & \\
\hline$\varnothing 16.50_{-0.15}^{+0.00}$ & 16.480 & & & & \\
\hline$\varnothing 21.65_{-0.50}^{+0}$ & 21.040 & & & & \\
\hline$\varnothing 18.50 \pm 0.20$ & 18.500 & & & & \\
\hline
\end{tabular}

Pada tabel 3 menunjukkan hasil pengukuran tutup kemasan minyak wangi secara average pada point 3 terdapat angka berwarna merah yaitu menunjukan pada bagian inspection tersebut yang menandakan dimensi inspection keluar dari batas basic dimension.

\section{IV.KESIMPULAN}

1. Hasil pengukuran tutup kemasan minyak wangi secara CPK (penyimpangan) mendapatkan hasil $0.89,0.08,-0.41$ dan 0.40 diantara nol dan satu menandakan rata-rata proses terletak dalam batas spesifikasi tetapi bagian variasi terletak diluar spesifikasi

2. Hasil Pengukuran tutup kemasan minyak wangi Secara average, terdapat angka yang berwarna merah yang menandakan dimensi inspection keluar dari basic dimensions khususnya pada point nomer 3 sample 1 sampai 5 semuanya keluar dari batas toleransi 
Volume 6 Nomor. 1, April 2021

P-ISSN : 2541-1179, E-ISSN : 2581-1711

Ojs :http://journal.uin-alauddin.ac.id/index.php/instek/index

Email : instek@uin-alauddin.ac.id

\section{DAFTAR PUSTAKA}

Purnami, 2017, Modul Tugas Besar Menggambar Teknik, Universitas Brawijaya

Ryan Fitria, 2011, Modul TKR, Menginterprestasikan Gambar Teknik, Yogyakarta

Pirnadi, 2008, Pengukuran Teknik, Universitas Mercu Buana

2020, Mesin Injeksi Molding, https://id.wikipedia.org/wiki/Injeksi_molding tanggal akses 9 April 2020.

2020, Pengertian Microsoft Excel dan Fungsinya, https://www.advernesia.com/blog/microsoft-excel/microsoft-exceladalah/comment-page-2/\#comments tanggal akses 6 Agustus 2020 